\title{
Relationship between Gerontological Nursing Students' Self Directed Learning Readiness and Learning Styles, Teaching Modes, and Academic Performance
}

\author{
Doaa El Sayed Fadila, Lecturer \\ Gerontological Nursing, Faculty of Nursing, Mansoura University \\ Eman Baleegh Meawad Elsayed, Lecturer \\ Gerontological Nursing, Faculty of Nursing, Mansoura University
}

\begin{abstract}
Self directed learning is a process in which students take the scheme to prepare learning goals, discover their learning needs, recognize resources for learning, choose and fulfill learning strategies, and appraise learning outcomes. Objective: Determine the relationship between gerontological nursing students' self directed learning readiness and learning styles, teaching modes, and academic performance. Setting: This study was carried out in the gerontological Nursing Department, Faculty of Nursing, Mansoura University. Subjects: A total number of 272 fourth year nursing students were enclosed within the study. Tools: Four tools were used for data collection; Nursing students' demographic data and academic performance structured questionnaire, Self-directed learning readiness scale (SDLR), VARK questionnaire, and teaching modes efficiency questionnaire. Results: Total mean score of self directed learning readiness was high among gerontological nursing students and self-control subscale mean score was high compared to other SDLR subscales. Kinesthetic and read -write styles were the most reported learning style by students. There were significant relations between gender, teaching modes efficiency and SDLR. Conclusion: The majority of gerontological nursing students prefer to learn using unimodal of VARK modalities and the dominant learning style was kinesthetic and read - write modal. No significant association between the students' marital status, residence, academic performance, learning styles, modal of learning and level of SDLR. Recommendations: Nursing educators should provide assistance and outlets for critical thinking, Problem based learning, brainstorming, self- direction and various types of creative thinking and move the students from traditional educational approaches to more active and autonomous approaches.
\end{abstract}

Keywords: Self directed learning readiness; learning styles; teaching moods; academic performance; gerontological nursing students.

\section{Introduction}

In Egypt and many other developing countries, the undergraduate students relied on traditional teacher based learning which is relied on remembering and rote memorizing. When attending bachelor programs, students are facing different styles of learning and teaching methods. Many courses of bachelor programs depend on self-directed learning which based on brainstorming, problem solving, and critical thinking. Students likely have many choices in the projects types that they will participate in and the way of learning and teaching that are used ${ }^{(1,2)}$. In context of nursing education specifically, science of nursing is rapidly changed, there is increased need for professional nurses to update their knowledge, become autonomous, capable of independent thought, and take their own decisions. Therefore, it is necessary for nursing students to be ready for self directed lifelong learning while they are still in academic life. Attention to self directed learning (SDL) has become ever more common place in the literature of education and considered as a critical educational goal $^{(3,4)}$. 
Self-directed learning is instructional learning method that helps nursing students to be ready for present as well as for the future challenges in the healthcare system. It is a "proactive process in which students formulate learning goals, diagnose their learning needs, identify resources for learning, select and implement learning plans, and evaluate learning results" ${ }^{\prime(5,6)}$. It includes different activities, as electronic dialogues, participation in study groups, self-guided reading, and reflective writing activities $^{(7)}$. Dimensions of SDL include self-management, self-control, and desire for learning. Self-management is defined as learners' ability to set and implement their own goals, and effectively manage resources and support available to them. Self-control determines learners' ability to evaluate self and determine their own learning goals and outcomes. Self control means the learners control the learning context to reach their learning objectives. It involves cognitive and meta cognitive processes that help individual to form the meaning of new concepts through adding to or adjusting current knowledge. While desire for learning refers to learners' preference for assuming responsibility for learning and their motivation for it $^{(8)}$.

The evidence refers to increase positive learning outcomes when the students take responsibility for their own learning through improving their awareness about their own learning style. Nursing students learning styles must be understood effectively to develop teaching methods that will result in shifting the control of the learning paradigm to the students ${ }^{(9,10)}$. Learning style is preferred way to learn by the individuals, it refers to the way of perception, interaction, and respond of the learner to the learning environments ${ }^{(11)}$. There are many factors affecting students' learning styles as genetic factors, culture, their previous learning experience, and the society they live in ${ }^{(12)}$. There are many models have been designed to assess learning styles of the students' personalities as well as the way they like to acquire information. The most sensory model which it is used as extension of the neuro-linguistic model is VARK. Fleming $(2008)^{(13)}$ stated that VARK deals with the way that students receive and give out information. In the VARK abbreviation, $\mathrm{V}$ refers for visual, $\mathrm{A}$ refers for aural, $\mathrm{R}$ refers for read/write, and $\mathrm{K}$ refers for kinesthetic preference. Learning through seeing information presented as flow charts or visual displays is preferable way by visual learners; while auditory learners prefer learning by hearing others and listening to lecture and oral sessions. Read and write learners study well through hand on activities as projects and use writing and drawing as memory aids; while kinesthetic learners prefer to learn by doing things involving many senses and tend to do physical activities ${ }^{(14)}$.

The faculty of nursing goal is to creatively implement teaching methods that are suitable with the preferred learning styles of their students. Teaching modes varies greatly; so nursing educators should recognize that learners differ in their learning styles and it is important to apply various teaching strategies to adapt and match students' learning styles ${ }^{(15)}$. Lecture is one of the traditional modes to teach a large group of students and an effective method of teaching in the lower-level cognitive domain. While tutorial is a teaching session given to one student or a small group of students. It is more specific and interactive than a lecture, a tutorial seeks to teach by giving example and supply the information to complete a certain task. There are numerous forms of tutorial, starting from a group of guidelines to accomplish a specific task to solving problems by an interactive session. However, practical learning requires students to perform procedures, record observation and interpret data. Nurse educators can integrate between these teaching modes ${ }^{(16)}$.

Ultimately, there are many tries for improvement of the student academic performance. Academic performance is one of the most significant and traditional 
impression about the students progression in education of nursing. Because higher achievement refers to higher practical skills, also the society consider it as an indicator of increasing chance to pursue higher education to get higher status occupations ${ }^{(17)}$. There are many methods measure students' academic performance, including their clinical performances in fieldwork, problem solving abilities, grade point average (GPA), and the completion of academic courses. Matching learning styles with learning framework, and improve SDL has resulted in achieving high levels of academic performance ${ }^{(18)}$.

Nurse educators must be aware of what factors influence how the nursing students learn through assessment of the learners. Assessment of learners is the first and the most important step in the instructional design, but it is also the step most likely to be neglected ${ }^{(19)}$. Understanding the relationships between SDL and learning styles are important for effective identification of learning needs, and facilitate the suitable delivery of supplies and methods for simplifying learning. Nurse educators are most effective when they help students in identifying and learning by using their own preferable style, developing certain learning actions that strengthen each style, help individual learners to get an available and accessible rich content and resources that will important for them, and provides guidance and outlets for various types of creative, critical thinking, and brainstorming. Additionally, nurse educators must help the nursing students to participate in their evaluation process, assisting them to identify their progression toward certain goals, and establishes ways to assess the limitations and benefits of their work $^{(20)}$. The understanding of SDLR and its relation to learning styles, teaching modes, and academic performance will enable the design of educational climates that will promote learner-centered approaches, which lead to the development of a feeling of accountability towards learning and fosters a sense of autonomy in professional lives of nursing students ${ }^{(21)}$.

\section{Aim of the Study}

This study aims to determine the relationship between gerontological nursing students' self directed learning readiness and learning styles, teaching modes, and academic performance.

\section{Research Questions}

1. What is the level of SDLR among Gerontological nursing students?

2. What are the preferred learning styles among Gerontological nursing students?

3. What are the most efficient teaching modes among Gerontological nursing students?

4. Are there any relation between SDLR and demographic characteristic, learning styles, teaching modes and academic performance of Gerontological nursing students?

\section{Materials and Method}

\section{Materials}

Design: Descriptive cross sectional research design was used in the present study.

Setting: The study was conducted at Gerontological Nursing Department, Faculty of Nursing, Mansoura University, Egypt.

Subjects: The study subjects comprised all fourth year nursing students (male and female) enrolled in a bachelor degree in nursing program (credit hours program, Gerontological nursing credit hours, 4 hours/week for a period of 14 weeks for theoretical and clinical content) during second semester of academic year 2017/2018. Total number of 272 nursing students out of 325 included in the study with a response rate of $83.7 \%$. Non responders had not attended the course or not interested in the study. 
Tools: Four tools were used for data collection to achieve the aim of the study as follow:

\section{Tool I: Nursing Students' Demographic} Data and Academic Performance Structured Questionnaire

It was developed by the researchers and included the following data:

- Students' age, gender, marital status, and place of residence.

- Academic performance was measured by GPA. GPA was an end of semester score produced by multiplying the grade of each course by the number of credit hours for that courses and then dividing this sum by the total number of credit hours for that student. The resulting averages were converted to a common 4.0 scale where score 4 to 3.3 is considered very high achievement, 3.2 to 2.0 is satisfactory achievement, while $<2$ is failed.

Tool II: Self-directed Learning Readiness $\underline{\text { Scale (SDLR) }}$

It was developed by Fisher \& king $(2010)^{(22)}$ to help nursing educators in determining student's abilities, attitudes, and personality characteristics necessary for selfdirected learning. The scale consists of 40 items grouped under three subscales namely; self-management which reflected characteristics of being able to manage one's own learning (13 items), desire for learning (12 items), and characteristic self-control or being in control of one's own learning (15 items). Students' responses were based on a 5-point Likert scale that ranged from strongly disagree $=1$ to strongly agree $=5$. Overall scores range from 40 to 200 , with higher scores indicating stronger readiness for self-directed learning among nursing students. Mean scores greater than 150 indicate a high level of SDLR while mean scores less than or equal to 150 represent a low level of SDLR. The scale was translated into Arabic and tested for its validity and reliability by Abu Assi and Alkorashy $(2016)^{(23)}$. The reliability was assured by the Cronbach's alpha coefficient $\alpha \geq 0.7$.

Tool III: VARK questionnaire (version $\underline{7.1)}$

It was developed by Fleming $(2008)^{(13)}$ to measure the learning style preferences of students. Version 7.1 of the VARK questionnaire includes 16 multiple choice questions, each with 4 choices. All choices correspond to the four sensory modalities measured by VARK (visual, aural/ auditory, $\mathrm{read} / \mathrm{write}$, and kinesthetic). Students can select multiple answers per question that match their perception then the number of responses selected corresponding to the different learning modalities based on the scoring chart sent by author is totaled and significance of differences is also calculated to determine the learning preference so they may be unimodal, or mutimodal (bimodal, trimodal or quadmodal). Arabic version of VARK questionnaire is available online at http://vark-learn.com/home-arabic/.

\section{Tool IV: Teaching modes efficiency} questionnaire

It was designed by Meehan-Andrews $(2009)^{(16)}$ to obtain students' feedback on their experiences of lectures, tutorials, practical, and integration classes and to decide if the objectives of these teaching modes were attained. The questionnaire comprise 16 statements, concerning four modes of teaching, namely; lectures (2 items), tutorials (4 items), practical (6 items) and integration (4 items). Students responded using a 5-point Likert scale that ranged from true none of the time $=1$ to true all of the time $=5$. Overall score ranges from 16 to 80 , with higher scores indicating the higher efficiency of teaching mode among students. Cut-off points were calculated. Score $0-<33 \%$ was considered low efficiency level of teaching mode, $33-<66$ $\%$ was considered moderate efficiency level and $>66 \%$ was considered high efficiency level of teaching mode. 


\section{Method}

- An official permission was obtained from the Vice Dean for Education and Student Affairs - Faculty of Nursing Mansoura University after clarifying the aim of the study.

- The study tool IV was translated into Arabic by the researchers.

- The tools were validated by a panel of five experts in related fields to ensure the content validity of the translated version with the original one. Suggestions of the jury members were followed and the tools were modified as indicated.

- A pilot study with $10 \%$ of the total sample was conducted to evaluate the clarity and feasibility of the tools and the time needed to complete the questionnaire. These students were excluded from the sample of the study.

- The reliability of tool III and IV was tested throughout the pilot study using test-retest measurement. Tools were applied on 10 students and were repeated again for these students after two weeks. The reliability was assured by means of Cronbach's coefficient alpha. It revealed that the tool III and IV have a reliability of 0.83 and 0.87 ; respectively.

- The study questionnaires were distributed to the target participants during class time.

- Students' academic performance (GPA) were obtained from the Faculty of Nursing records.

- The time required to complete the study tools was 20 minutes.

- Data were collected during four months duration from the mid of February to the mid of June 2018.

\section{Ethical considerations:}

Approval of ethics committee to carry out the study was obtained from the authority of Faculty of Nursing, Mansoura University. Informed consent was obtained from the students after explanation of the purpose of the study. Students were informed that their sharing was voluntary and had the flexibility to withdraw from the study at any time. The questionnaire data were kept confidential.

\section{Statistical Analysis}

Data were analyzed using SPSS program version 16. Qualitative variables were presented as number and percent. Chisquared test was used testing significance between groups. Quantitative variables were presented as mean and SD. Unpaired t-test was used for testing significance between two groups, and ANOVA (F) test was used for more than two groups' comparisons. Pearson's correlation coefficient was used to calculate correlation between different variables. $\quad \mathrm{P} \leq 0.05$ was considered statistically significant differences.

\section{Results}

Table (1) shows demographic characteristics and academic performance of gerontological nursing students. The table revealed that mean age of the studied students were $21.7 \pm 0.53$ years. Female constituted $60.3 \%$ of the students. Most of students were single and live in rural area (87.1\%, 69.1\%; respectively). As regards to academic performance $52.9 \%$ of them had very high achievement with a mean of $3.3 \pm 0.31$.

Table (2) shows learning style, learning modal, and teaching modes efficiency of gerontological nursing students. The table revealed that $22.1 \%$ of the students preferred read -write and kinesthetic style followed by aural and visual style (18\%, 4.8\%; respectively). Concerning learning modal and teaching modes efficiency, about $66.9 \%$ of the students preferred unimodal learning style, whereas practical teaching mode was the most efficient mode of teaching with a mean of $21.2 \pm 5.3$, followed by integration, 
tutorial, and lecture $(13.6 \pm 3.5,11.4 \pm 4.0$, and $6.7 \pm 1.9$; respectively).

Figure (1) shows the teaching modes efficiency levels among gerontological nursing students. It was observed from the figure that the highest efficient level of teaching mode reported by gerontological nursing students was practical mode $(41.1 \%)$, followed by tutorial, lecture, and integration $(40.4 \%, 38.6 \%$, and $34.9 \%$; respectively).

Table (3) shows relationship between gerontological nursing students' SDLR and their demographic characteristics, academic performance, learning styles and learning modal. The table revealed that self-control subscale had the highest mean score (60.0 \pm 9.9$)$, followed by desire for learning

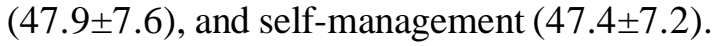
The gender was the only demographic variable that affect significantly on students' readiness for self directed learning. No statistically significant relations were found between overall or subscales mean scores of self-directed learning readiness and academic performance, learning styles, or learning modal.

Table (4) displays correlation coefficients (r) between gerontological nursing students' SDLR and teaching modes efficiency. It was observed from the table that there were significant correlations between overall and subscales mean scores of self-directed learning readiness and teaching modes efficiency. While there was no significant correlation between tutorial teaching mode and desire for learning.

Table (5) shows the level of SDLR of gerontological nursing students according to demographic characteristics, academic performance, learning styles, and learning modal. The table displays that high level of SDLR was reported by nearly two thirds of the students $(65.4 \%)$, while $34.6 \%$ of them reported low level of readiness. There was statistically significant relation between SDLR level and gender $(\mathrm{P}=0.015)$. On the other hand, level of SDLR was not affected by demographic characteristics, academic performance, learning styles, or learning modal.

\section{Discussion}

Self-directed learning, learning style, and teaching modes efficiency are essential parts of nursing education as they aid nurse educators to expect variations in learners' interests, abilities, and needs to learn. Furthermore, they help nurse educators to develop educational climates that will design curricula, adopt teaching methods needed for lifelong learning, and promote learnercentered strategies ${ }^{(24)}$.

The current study revealed that, the mean total score of SDLR was high (155.3 \pm 20.9$)$. One explanation for this high mean score of overall SDLR might be that Egyptian policy for high education underlines student centered learning approach, which supports learning and teaching process to assist self directed learners. Previous studies carried out in Saudi Arabia by El-Gilany \& Abusaad $(2013)^{(21)}$ and Abu Assi and Alkorashy $(2016)^{(23)}$, in China by Yuan et al. $(2012)^{(25)}$, and in Australia by Fisher et al. $(2001)^{(26)}$ reported the same results. Moreover, the current study's findings reflect those of Jordanian study by Abu-Moghli et al. $(2005)^{(27)}$ who showed that nursing students could identify their goal independently, were visible as independent and autonomous learners, had a desire to learn things, and were inquisitive to learn. Additionally, the current study results revealed that the highly reported subscale for SDLR among gerontological nursing students at Mansoura University was self-control subscale followed by desire for learning while self management subscale was the lowest. The high score for self control subscale reflects great maturity and confidence of nursing students while the lowest score for the self management subscale shows that there is increasing room for improving and supporting students in self management skills. This result is in congruent with $\mathrm{El}$ 
Seesy et al. (2017) ${ }^{(28)}$ in Egypt, Solimanand Al shaikh (2015) ${ }^{(29)}$ in Saudi Arabia and Smedely $(2007)^{(30)}$ in Australia who reported that nursing students attain the highest score on self control dimension and lowest score on self management dimension. However, this result contradict with Williams et al. $(2013)^{(31)}$ who confirmed that the moderate mean scores for each self management and self control subscale while the highest mean score was for the desire for learning subscale.

Students show to have a preferred learning style derived from their sensory intake of information. Current theories of learning though favor the use of global or multisensory approach for classroom instruction. In this approach the learner's desired style is used to attract him and begin instruction, and then his learning is strengthened through other styles. Students are now anticipated to become lifelong learners and as such, they must recognize their preferred learning styles to better handle what they learn and how they learn. Students must identify how to adjust to fit the information they are learning ${ }^{(32)}$. From this standpoint, finding from the current study revealed that, more than two thirds of gerontological nursing students preferred to learn using only unimodal learning and nearly one third preferred two modes of learning styles. Moreover, most students who used a single modality preferred the kinesthetic and read-write followed by aural mode. This may be due to many courses of nursing programs depending on hand on learning, clinical practice, teacher-centered and lecture-based approach. This in agreement with a study conducted in Saudi Arabia by Stirling and Alquraini $(2017)^{(2)}$ who found that approximately $56.1 \%$ of nursing students had unimodal learning style and the most preferred learning style was kinesthetic. In the same line, Abou Shousha and Abd El Rahman (2014) ${ }^{(33)}$ in Egypt concluded that the majority of students had a unique learning approach of learning and kinethetic learning style was the most suitable style for them, followed by visual, $\mathrm{read} / \mathrm{write}$ and aural. In the same line, this result is constant with the result of previous researches by Meehan-Andrews (2009) ${ }^{(16)}$ in Australia and Alaka (2011) ${ }^{(24)}$ in USA, who stated that most students prefer a unimodal learning style; followed by two modes. Furthermore, a study carried out by Mohamed \& Helal (2012) $)^{(34)}$ in Egypt discovered that the majority of both Faculty of Nursing and Technical Institute of Nursing students were unimodal learning style and they were aural and read and write learning style. They justified that, bachelor's degree nursing students are participated in an educational striving toward providing a complex nursing care requiring problem solving techniques and specialized skills so, these learning styles might help them in learning.

Nursing education is a compound activity that merges art and science of clinical practice and nursing process into the teaching learning process. The use of a variety of teaching modes aids in meeting the needs of diverse types of students. In this respect, the students in the current study reported that practical followed by integration were the most efficient teaching modes. Tutorial were the third most efficient teaching method followed by lectures. This may be due to nursing students are more prone to the practical areas where they learn actively how to perform nursing tasks which is useful for them when working. Additionally, tutorials are a very effective way of providing students with question time sessions or feedback; and that they can be structured, problem based or group work, or relaxed where students can inquire any question on any topics. This agree with Meehan-Andrews (2009) ${ }^{(16)}$ who stated that practical mode of teaching helped students comprehend lecture material; and that connecting concepts introduced during lectures and then further explored during practical sessions. A study conducted by Abou Shousha and Abd El Rahman $(2014)^{(33)}$ in Egypt indicated that integration mode of teaching followed by tutorials were the most useful teaching methods reported 
by students. They rationalized that, it may be related to the point of view of nursing students that by integrating the three teaching modes, learning will be achieved efficiently, as through tutorial and practical the implementation of theoretical content is attained $^{(33)}$.

The total self directed learning readiness mean score and its subscales showed no significant relations with students' demographic characteristics except for gender. Generally, the finding of the current study revealed that the mean score of self management subscale, self- control subscale and the total mean score of SDLR showed significant relation with students' gender while desire for learning had no significant association. This agrees with a study conducted by McCollin (2000) ${ }^{(35)}$ in USA who revealed that gender is a factor that affect student-centered behavior. In the same direction, Chen et al. (2006) ${ }^{(36)}$ in Taiwan, Roberson and Merriam (2005) ${ }^{(37)}$ in USA and El-Gilany \& Abusaad $(2013)^{(21)}$ in Saudi Arabia found that students' demographics were not associated with SDLR. Yet, AbuAssi and Alkorashy $(2016)^{(23)}$ in Saudi Arabia concluded that age, gender, and academic level influenced SDL ability. This discrepancy denotes that the demographic factors may have diverse effects in varied situations. Moreover, Alkorashy and Abu Assi (2016) ${ }^{(38)}$ in Saudi Arabia found that students' age and academic levels were significantly associated with SDLR and its related subscales. They rationalized that, in the first academic year, nursing students are told about their tasks and roles and lectured on the significance of education and the need to learn to be successful in the nursing program. In the second and third academic years, changes in the students' SDLR levels may indicate their awareness of the learning approach and decreased focus on understanding how to learn. Fourth- or lastyear students have more experience and clinical practice in diverse clinical settings. The learners in this final year are responsible for facilitating discussion and sharing their opinions, making decisions, and working independently on special clinical situations ${ }^{(20)}$. With each year, the level of SDL activities increases, and students need to adapt to survive which confirming the nature of the maturation process in the development of SDL. While in the current study the insignificance of the association may be due to the age range being too small and all participants are in the same academic level. A larger age range might be required in order to reveal the association between the two variables.

Regarding academic performance, the current study revealed that, there was no statistically significant relation between the total mean score of SDLR and its subscales and academic performance of gerontological nursing students. Several factors may have influenced the relationship between SDLR and academic performance in current study. Students performed well in courses overall, which suggests that students are able to learn foundational knowledge in spite of their SDLR. Additionally, the grades distribution focused mainly on non-self-directed learning activities. These activities were greatly weighted because skill demonstrations were primary courses' objectives. Therefore, SDLR and learning habits may not be important predictors of academic success when students are given exact expectations and told the knowledge and skills to be learned. Contrary, In Turkey, Avdal $(2013)^{(39)}$ conducted a study to analyze the association between students' total SDL scores and their achievement level and revealed that a positive modest association was noted between the standard successful grade and the students' SDL capability.

Overall, the current study findings showed that there was no relation between SDLR and learning styles of gerontological nursing students. This is in agreement with studies conducted in Saudi Arabia by ElGilany \& Abusaad $(2013)^{(21)}$, and in Iran by Safavi et al. (2010) ${ }^{(40)}$, which revealed that the SDLR score and levels had no influence on learning style. In contrast, Linares 
$(1999)^{(41)}$ in USA found that SDLR did effect the learning style of students and the convergers, who prefer thinking and doing things, were more effective self - directed learners. This discrepancy may be attributed to different learning approaches in different institutions and students' different learning experiences. In addition, the study revealed that teaching modes efficiency correlate significantly and positively with SDLR. Thus, the more efficient the teaching modes, the higher the level of SDLR. In the same line, a study done in China found that $51 \%$ of the nursing students implemented smallgroup studying procedures, problem-based learning (PBL), and SDL, and 62.3\% of the students demonstrated elevated levels of SDLR. In that study, many of the students who employed small-group learning, PBL, and SDL had higher levels of SDLR than those who used different learning methods ${ }^{(20)}$.

Regarding SDLR level, nearly two thirds of students had high levels of SDLR (score $\leq 150$ ). Additionally, residence, marital status, GPA, Learning style, and modal exert no significant effect on the level of SDLR. On the other hand, gender had significant effect on the level of SDLR. This finding is in agreement with the results of many prior studies carried out in Saudi Arabia by ElGilany \& Abusaad (2013) ${ }^{(21)}$,Thailand by Klunklin et al. $(2010)^{(42)}$, and USA by Linares $(1999)^{(41)}$ they stated that most of nursing students have high levels of SDLR.Abu-Moghli et al. (2005) $)^{(27)}$ and Safavi et al. $(2010)^{(40)}$ reported that the majority of Jordian and Iranian nursing students perceived themselves as independent learner and had high level of SDLR. Another study done in China reported that $62.3 \%$ of baccalaureate nursing students stated high level of SDLR with significant difference with gender ${ }^{(25)}$. Contrary, Fisher et al.'s (2001) ${ }^{(26)}$ concluded that more than 150 students indicated low levels of SDLR. These results also disagreed with the study of Abu Assi and Alkorashy $(2016)^{(23)}$ who concluded that more than half of the participants had low levels of SDLR.
The difference among students in their SDLR might be due to individual demographical variations, which may affect their incentive to learn, learning goals, responses to the classroom and clinical practice environments, and attitudes towards teaching and teachers. Such factors could affect their dominant styles of learning as well as their readiness for $\mathrm{SDL}^{(43,44)}$. In the same way, Yuan et al. $(2012)^{(25)}$ reported that the increased level of SDLR might point out increased relative autonomy in clinical practice and highlighting on selfresponsibility, thereby helping students to train them for the start of their nursing careers and perform adult roles. In the same context, Ahmad \& Majid (2010) ${ }^{(45)}$ stated that the cultural background of the nursing students is also an affecting factor in the development students' SDL skills.

\section{Conclusion}

This study concluded that the majority of gerontological nursing students had high level of SDLR and self-control was the highest dimension of SDLR reported by students. The most students prefer to learn using unimodal of VARK modalities and the most preferred learning style was kinesthetic and read - write modal. The results revealed no significant connection between the students' marital status, residence, academic performance, learning style, mode of learning and level of SDLR. Yet, there was significant relation between gender, teaching modes efficiency and SDLR.

\section{Recommendations}

Based on the main findings of this study, we can recommend that:

- Nursing educators should provide assistance and outlets for critical thinking; problem based learning, brainstorming, self- direction and various types of creative thinking and move the students toward more active and autonomous educational approaches instead of traditional one. 
- Additional efforts to support students' management skills and resources should be considered for independent practice and education.

- Nurse educators should support their students in identifying and learning through their own preferred learning style, and they can develop specific learning activities that support each style.

- Nursing educators should know the teaching materials and methods with which a learner is most comfortable, and modify teaching to meet the student's needs with different styles of learning, thus enhancing their readiness to learn.
- Additional studies are needed to replicate this study using larger sample size, and assess factors affecting SDLR.

- Further studiesto assess SDLR in post graduate students and compared with undergraduate program.

\section{Acknowledgement}

The authors are grateful to all fourth year gerontological nursing students for their participation in fulfillment of this study. 
Table (1): Demographic characteristics, and academic performance of gerontological nursing students $(\mathbf{N}=272)$

\begin{tabular}{|l|c|}
\hline & $\mathbf{N}(\%)$ \\
\hline Age & Mean \pm SD \\
& $21.7 \pm 0.53$ \\
\hline Gender & \\
Male & $108(39.7)$ \\
Female & $164(60.3)$ \\
\hline Marital status & \\
Single & $237(87.1)$ \\
Married & $35(12.9)$ \\
\hline Residence & \\
Urban & $84(30.9)$ \\
Rural & $188(69.1)$ \\
\hline Academic performance (GPA) & $128(47.1)$ \\
Satisfactory achievement (3.2- 2) points & $144(52.9)$ \\
Very high achievement (4-3.3) points & Mean \pm SD \\
& $3.3 \pm 0.31$ \\
\hline
\end{tabular}

Table (2): Learning styles, learning modal, and teaching modes efficiency of gerontological nursing students $(\mathrm{N}=\mathbf{2 7 2})$

\begin{tabular}{||c|c|}
\hline & $\mathbf{N}(\boldsymbol{\%})$ \\
\hline Learning styles & \\
Aural & $49(18.0)$ \\
Read-write & $60(22.1)$ \\
Visual & $13(4.8)$ \\
Kinesthetic & $60(22.1)$ \\
Aural and Kinesthetic & $26(9.6)$ \\
Aural and read-write & $21(7.7)$ \\
Visual and Kinesthetic & $6(2.2)$ \\
Read-write and visual & $6(2.2)$ \\
Aural and visual & $8(2.9)$ \\
Read-write and Kinesthetic & $9(3.3)$ \\
Aural, Read- Write and Kinesthetic & $9(3.3)$ \\
Aural, Visual, and Kinesthetic & $5(1.8)$ \\
\hline Learning modal & \\
Unimodal & $182(66.9)$ \\
Bimodal & $76(28)$ \\
Trimodal & $14(5.1)$ \\
\hline Teaching modes efficiency & Mean \pm SD \\
Lecture & $6.7 \pm 1.9$ \\
Tutorial & $11.4 \pm 4.0$ \\
Practical & $21.2 \pm 5.3$ \\
Integration & $13.6 \pm 3.5$ \\
\hline
\end{tabular}




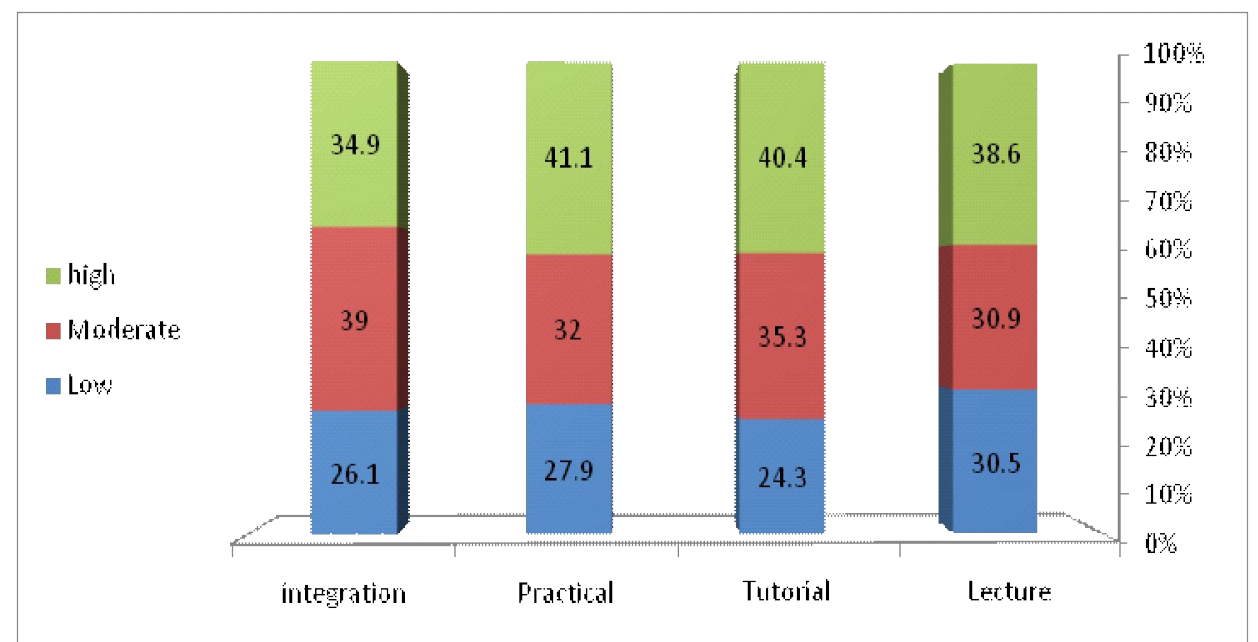

Figure (1): Teaching modes efficiency levels among gerontological nursing students

Table (3): Relationship between gerontological nursing students' SDLR and their demographic characteristics, academic performance, learning styles and learning modal

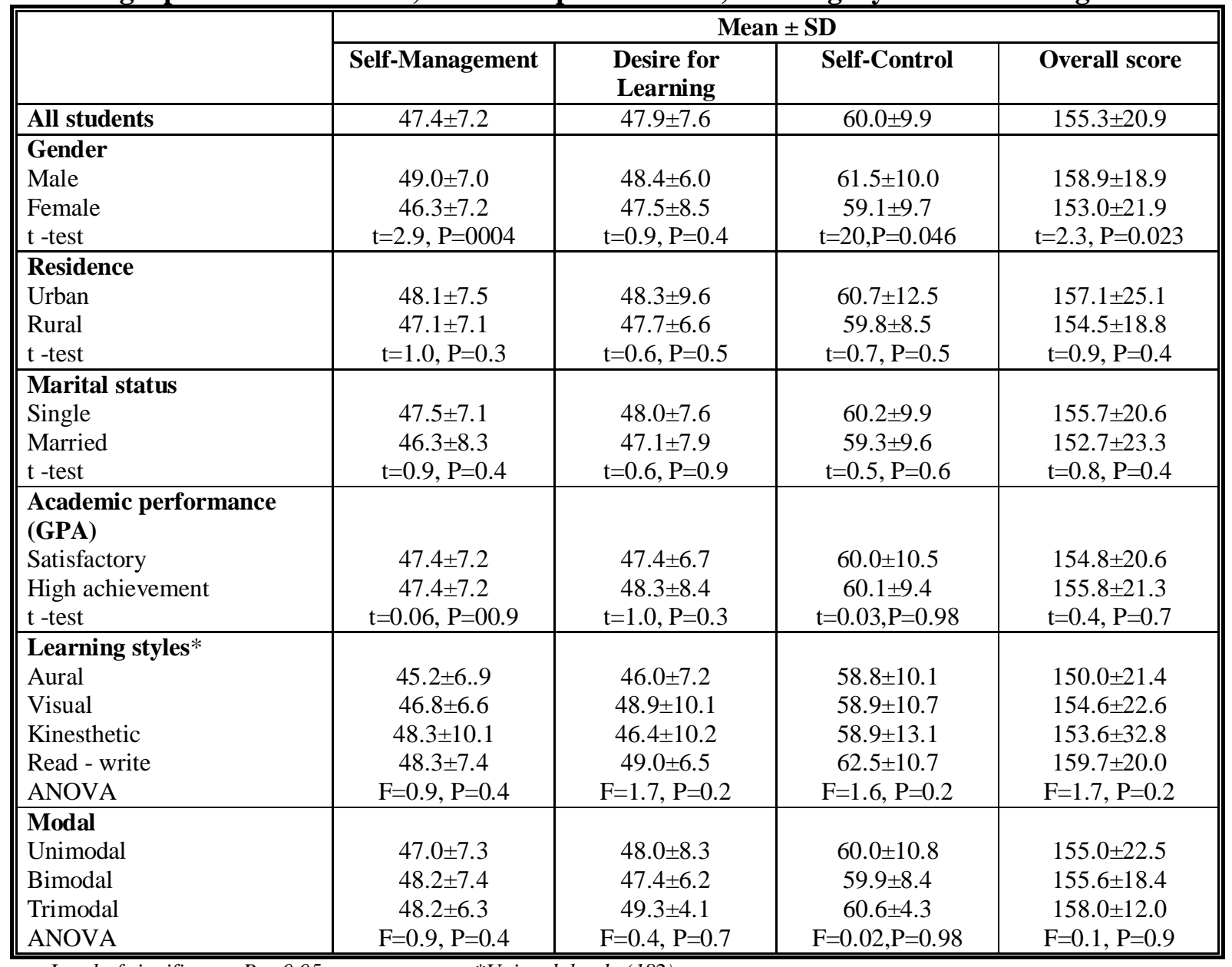


Table (4): Correlation coefficients ( $r$ ) between gerontological nursing students' SDLR and teaching modes efficiency

\begin{tabular}{|l|c|c|c|c|}
\hline \hline & $\begin{array}{c}\text { Self- } \\
\text { Management }\end{array}$ & $\begin{array}{c}\text { Desire for } \\
\text { Learning }\end{array}$ & Self-Control & Overall score \\
\hline Lecture & $0.21^{* * *}$ & $0.23^{* * *}$ & $0.021^{* * *}$ & $0.25^{* * *}$ \\
\hline Tutorial & $0.26^{* * *}$ & 0.1 & $0.16^{* * *}$ & $0.2^{* * *}$ \\
\hline Practical & $0.26^{* * *}$ & $0.22^{* * *}$ & $0.25^{* * *}$ & $0.29^{* * *}$ \\
\hline Integration & $0.3^{* * *}$ & $0.18^{* *}$ & $0.21^{* * *}$ & $0.79^{* * *}$ \\
\hline
\end{tabular}

**,*** significant correlation at $P \leq 0.01 \& 0.001$; respectively

Table (5): Level of SDLR of gerontological nursing students according to demographic characteristics, academic performance, learning styles, and learning modal

\begin{tabular}{|c|c|c|c|c|}
\hline & Total & $\begin{array}{l}\text { Low level of self- } \\
\text { directed learning } \\
\text { readiness } \\
\text { N }(\%) \\
\end{array}$ & $\begin{array}{c}\text { High level of self- } \\
\text { directed learning } \\
\text { readiness } \\
\mathbf{N}(\%) \\
\end{array}$ & Sig. test \\
\hline All students & 272 & $94(34.6)$ & $178(65.4)$ & \\
\hline $\begin{array}{l}\text { Gender } \\
\text { Male } \\
\text { Female }\end{array}$ & $\begin{array}{l}108 \\
164\end{array}$ & $\begin{array}{l}28(25.9) \\
66(40.2)\end{array}$ & $\begin{array}{l}80(74.1) \\
98(59.8)\end{array}$ & $\chi 2=5.9, P=0.015$ \\
\hline $\begin{array}{l}\text { Residence } \\
\text { Urban } \\
\text { Rural }\end{array}$ & $\begin{array}{c}84 \\
188\end{array}$ & $\begin{array}{l}28(33.3) \\
66(35.1)\end{array}$ & $\begin{array}{c}56(66.7) \\
122(64.9)\end{array}$ & $\chi 2=0.1, P=0.8$ \\
\hline $\begin{array}{l}\text { Marital status } \\
\text { Single } \\
\text { Married }\end{array}$ & $\begin{array}{c}237 \\
35\end{array}$ & $\begin{array}{l}82(34.6) \\
12(34.3)\end{array}$ & $\begin{array}{c}155(65.4) \\
23(65.7)\end{array}$ & $\chi 2=0.001, P=0.97$ \\
\hline 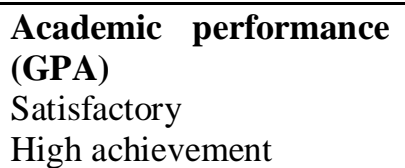 & $\begin{array}{l}128 \\
144\end{array}$ & $\begin{array}{l}48(37.5) \\
45(31.2)\end{array}$ & $\begin{array}{l}80(62.5) \\
99(68.8)\end{array}$ & $\chi 2=0.9, P=0.34$ \\
\hline $\begin{array}{l}\text { Learning style* } \\
\text { Aural } \\
\text { Visual } \\
\text { Kinesthetic } \\
\text { Read and write }\end{array}$ & $\begin{array}{l}49 \\
60 \\
13 \\
60\end{array}$ & $\begin{array}{c}22(44.9) \\
22(36.7) \\
5(38.5) \\
16(26.7)\end{array}$ & $\begin{array}{l}27(55.1) \\
38(63.3) \\
8(61.5) \\
44(73.3)\end{array}$ & $\chi^{2}=4.0, P=0.3$ \\
\hline $\begin{array}{l}\text { Modal } \\
\text { Unimodal } \\
\text { Bimodal } \\
\text { Trimodal }\end{array}$ & $\begin{array}{c}182 \\
76 \\
14\end{array}$ & $\begin{array}{c}65(35.7) \\
26(34.2) \\
3(21.4)\end{array}$ & $\begin{array}{c}117(64.3) \\
50(65.8) \\
11(78.6)\end{array}$ & $\chi 2=1.2, P=0.6$ \\
\hline
\end{tabular}

Level of significance $P<0.05$

*Unimodal only (182) 


\section{References}

1. Alharbi HA. Readiness for selfdirected learning: How bridging and traditional nursing students differs? Nurse education today $2018 ; 61: 231$ 234.

2. Stirling BV, Alquraini WA. Using VARK to assess Saudi nursing students' learning style preferences: Do they differ from other health professionals? Journal of Taibah University Medical Sciences.2017; 12(2):125-130.

3. Gyawali S, Jauhari AC, Shankar PR, Saha A, Ahmad M. Readiness for self-directed learning among first semester students of a medical school in Nepal. Journal of Clinical and Diagnostic Research. 2011; 5(1): 20 23.

4. National League of Nursing. (2005). Core competencies of nurse educators with task statements. Available at: http://www.nln.org/professionaldevelopment-programs/competenciesfor-nursing-education, PDF. Accessed 1 May 2018.

5. Cheng S, Kuo C, LinK, Lee-Hsieh J. Development and preliminary testing of a self-rating instrument to measure self-directed learning ability of nursing students. International Journal of Nursing Studies. 2010; 47 (9): 1152-1158.

6. Alotaibi KN. The learning environment as a mediating variable between self-directed learning readiness and academic performance of a sample of Saudi nursing and medical emergency students. Nursing Education Today 2016; 36:249-254.

7. O'Shea E. Self-directed learning in nurse education: a review of the literature. Journal of Advanced Nursing. 2003; 43 (1): 62-70.
8. Garrison DR. Self-directed learning: toward a comprehensive model. Adult Education Quarterly. 1997;48(1):1833

9. Vorhaus J. Learning styles in vocational education and training. In: Penelope P, Eva B, \& Barry M. (Eds.). International Encyclopedia of Education. Oxford: Elsevier, pp. 2010; 376-82.

10. Fritz M. Using learning styles inventories to promote active learning ${ }^{\text {ee }}$. Journal of College Reading and Learning 2002; 32(2): 183-9.

11. Bastable S. B. Nurse as Educator: Principles of Teaching and learning. Boston. Jones and Bartlett, 2010.

12. Verster C. (2010). Learning styles and teaching. Available at: http://www.teachingenglish.org.uk/arti cle/learning-stylesteaching. Accessed 28 March 2018.

13. Fleming ND. VARK. A Guide to Learning Styles 2008. Available at: http://www.varklearn.com/english/page.asp?p=questio nnaire.

14. Fleming S, McKee G, Huntley-Moore $S$. Undergraduate nursing students' learning styles: A longitudinal study. Nurse Education Today 2011; 31(5):444-449.

15. Aripin R, Mahmood Z, Rohaizad R, Yeop U, Anuar M. Students'learning styles and academic performance. Proceedings of the Annual SAS Malaysia Forum; 2008 July 15; Kuala Lumpur,Malaysia. Available at: http://www.sas.com/offices/asiapacifi c/malaysia/events/sasforum/zurina.pdf

16. Meehan-Andrews TA. Teaching mode efficiency andlearning preferences of first year nursing students. 
NurseEducation Today 2009; 29 (1): 24-32.

17. Lounsbury JW, Levy JJ, Park SH, GibsonLW, \& Smith R. An Investigation of the Construct Validity of the Personality Trait of SelfDirected Learning. Learning and Individual Differences, (2009); 19: 411-418. Available at: http://dx.doi.org/10.1016/j.lindif.2009. $\underline{03.001}$

18. Brown T. Learning style preferences of occupational therapy,physiotherapy and speech pathology students: a comparativestudy. IJAHSP 2008; 6: 112.

19. Brown T. Learning style preferences of occupational therapy, physiotherapy and speech pathology students: a comparative study. International Journal of Allied Heath Sciences and Practice 2008; 6: 1-12.

20. Aripin R, Mahmood Z, Rohaizad R, Yeop U, Anuar M. Students' learning styles and academic performance. Proceedings of the Annual SAS Malaysia Forum; 2008 July 15; Kuala Lumpur, Malaysia. Available at: http://www.sas.com/offices/ asiapacific/malaysia/events/sasforum/ zurina.pdf

21. El-GilanyA-H, Abusaad FES. Selfdirected learning readiness and learning styles among Saudi undergraduate nursing students. Nurse Education Today 2013; 33:1040-1044.

22. Fisher MJ, King J. The self-directed learning readiness scale for nursing education revisited: A confirmatory factor analysis. Nurs Educ Today 2010;30:44-48.

23. AbuAssi NE, Alkorashy HE. Relationship between learning style and readiness for self-directed learning among nursing studentsat king Saud university, Saudi Arabia.
International Journal of Advanced Nursing Studies 2016; 5 (2): 109-116.

24. Alaka AM. Learning styles: what difference do the differences make? Charleston Law Review 2011; 5 (2): 133-172.

25. Yuan HB, Williams BA, Fang JB, Pang D. Chinese baccalaureate nursing students' readiness for selfdirected learning. Nurse Education Today 2012; 32(4): 427-431.

26. Fisher M, King J, Tague G. Development of a self-directed learning readiness scale for nursing education. Nurse Education Today 2001; 21(7): 516-525.

27. Abu-Moghli F, Khalaf I, Halabi J, Wardam L. Jordanian baccalaureate nursing students' perception of their learning styles. International Nursing Review 2005; 52(1): 39-45.

28. El Seesy NA, Sofar SM, Al-Battawi JA. Self-directed learning readiness among Nursing Students at KingAbdulazizUniversity, Saudi Arabia. IOSR Journal of Nursing and Health Science.2017, 6(6): 14-24.

29. Soliman M, Al-shaikh G. Readiness for self -directed learning among first year Saudi medical students: a descriptive study. Pak Medical Science Journal. 2015; 31(4): 799802.

30. Smedley A. The self-directed learning readiness of first year bachelor of nursing students. Journal of Research in Nursing. 2007; 12(4): 373-85.

31. Williams B, Boyle M, Winship C, Brightwell R, Devenish S, Munro G. Examination of self-directed learning readiness of paramedic undergraduates: A multi-institutional. Study Journal of Nursing Education and Practice. 2013; 3 (2): 103-11. 
32. Salehi SH. Nursing Students' Preferred Learning Styles .Journal of Medical Education 2007; 11(3 \& 4): 85-89.

33. Abou Shousha AA, Abd El Rahman RM. Learning Styles of Nursing Administration Students and Their Teaching Mode Efficiency. Life Science Journal 2014;11(2s): 236-246.

34. Mohamed A, Helal H. Learning Styles of Community Health Nursing Students' at Faculty of Nursing and Technical Institute of Nursing - In Alexandria. New York Science Journal2012; 5(4): 28-37.

35. McCollin E. Faculty and student perceptions of teaching style: do teaching styles differfor traditional and nontraditional students? Presented at: Annual Conference ofMid-South Educational Research Association. (Bowing Green, KY, November1517). Available at: http://www.eric.ed.gov/PDFS/ED4471 39.pdf. Accessed at 2 March 2018.

36. Chen YF, Wang CM, LinHJ. Explore the relationships among demography, personality traits and self-directed learning. Journal of Human Resources and Adult Learning 2006. Available at:

http://www.hraljournal.com/Page/19\% $20 \mathrm{Yu}-\mathrm{Fen} \% 20 \mathrm{Chen} . \mathrm{pdf}$.

37. Roberson DNJ, Merriam SB. The selfdirected learning process of older, rural adults. Adult Education Quarterly 2005; 55 (4): 269-287.

38. Alkorashy HA, Abu Assi NE. Readiness for Self-Directed Learning among Bachelor Nursing Students in Saudi Arabia: A Survey-Based Study. International Journal of Nursing Education and Research2016; 4(2): 187-194.

39. Avdal EÜ. The effect of self-directed learning abilities of student nurses on success in Turkey. Nurse Education Today, 2013; 33(8): 838-841.

40. Safavi M, Shooshtari SH, Mahmoodi M, Yarmohammadian M. Selfdirected learning readiness and learning styles among nursing students of Isfahan University of Medical Sciences. Iranian Journal of Medical Education 2010; 10(1): 2735 .

41. Linares AZ. Learning styles of students and faculty in selected health care professions: Comparative Study. Journal of Nursing Education 1999; 38(9): 407-414.

42. Klunklin A, Viseskul N, Sripusanapan A, Turale S. Readiness for self-directed learning among nursing students in Thailand. Nursing and Health Sciences 2010; 12(2): 177-181.

43. Felder RM, Brent R. Understanding student differences. Journal of Engineering Education 2005; 94(1): 5772.

44. Kim S, McLean GN. The impact of national culture on in-formal learning in the workplace. Adult Education Quarterly 2014; 64(1): 39-59.

45. Ahmad BE, Majid FA. Self-directed learning and culture: A study on Malay adult learners. Procedia-Social and Behavioral Sciences 2010; 7: 254-263. 